\title{
Effect of low level contamination on TiAl alloys studied by SIMS
}

\author{
O.M.N.D. Teodoro ${ }^{\mathrm{a},}{ }^{*}$, J. Barbosa ${ }^{\mathrm{b}}$, M. Duarte Naia ${ }^{\mathrm{c}}$, A.M.C. Moutinho ${ }^{\mathrm{a}}$ \\ ${ }^{a}$ CEFITEC, Departamento de Física da Universidade Nova de Lisboa, 2829-516 Caparica, Portugal \\ ${ }^{\mathrm{b}}$ CITEPE, Universidade do Minho, Campus de Azurém, 4800-058 Guimarães, Portugal \\ ${ }^{\mathrm{c}}$ Departamento de Física, Universidade de Trás-os-Montes e Alto Douro, 5001-911 Vila Real, Portugal
}

Available online 6 May 2004

\begin{abstract}
Titanium aluminides are a valuable alternative to superalloys in applications where the ratio resistance/density is important. Since the ordinary production routes lead to high final costs, an alternative might be the use of traditional casting techniques by induction melting of the alloy in a ceramic crucible and pouring into ceramic moulds, made by the investment casting process. However, due to the high reactivity of Ti alloys, the use of traditional ceramic materials cannot be used, as they lead to oxide formation and oxygen pick up from both the crucible and the moulding materials.

In this work, the effect of low level contamination was studied by SIMS. Special attention was given to the oxygen concentration for samples obtained with different mould materials. The comparison of SIMS in-depth profiles with hardness profiles, gives insight concerning the significance of the oxygen concentration in the properties of the alloy and regarding the choice of the most suitable materials for TiAl production.
\end{abstract}

C) 2004 Elsevier B.V. All rights reserved.

Keywords: Alloys; TiAl; Casting techniques; Oxygen contamination

\section{Introduction}

During the last decade several intermetallic alloy systems have been identified as potential candidate materials for high temperatures applications. Among those systems, $\gamma$-TiAl was found to be a very promising material. Together with excellent mechanical and corrosion properties at high temperatures, such characteristics are very attractive for applications in the aeronautical, aerospace and automotive industries. Nevertheless, its current high cost significantly limits its application at an industrial-scale with success. Titanium aluminides also suffer from quite low duc-

\footnotetext{
* Corresponding author. Tel.: +351-21-294-85-76; fax: +351-21-294-85-49.

E-mail address: odt@fct.unl.pt (O.M.N.D. Teodoro).
}

tility at room temperature and their application is always dependent from the microstructure modification. The best compromise between high temperature properties and room temperature ductility is achieved with a two-phase microstructure $\left(\alpha_{2}+\gamma\right)$, for a volume ratio $\alpha_{2} / \gamma$ between 5 and $15 \%$. This compromise is often achieved by decreasing the aluminium content of the alloy and adding small amounts of alloying elements, such as $\mathrm{Cr}, \mathrm{Mn}, \mathrm{V}$ and $\mathrm{B}$, which were found to refine the grain size and stabilize the lamellar structure [1,2].

$\gamma$-TiAl is extremely reactive with almost every known elements, with particular affinity to oxygen and nitrogen, which dissolves interstitially, leading to a strong hardness increase and alloy embrittlement. The maximum solubility of oxygen in the $\gamma$ phase is about 250 at.ppm and more than 2.1 at. $\%$ in $\alpha_{2}$ phase 
and it does not depend on the $\gamma$-TiAl alloy composition [3]. According to other researchers [1,3], such difference in the oxygen solubility limits, is the most important factor to explain the higher ductility of twophase $\left(\alpha_{2}+\gamma\right)$-TiAl alloys when compared with single phase $\gamma$-TiAl. Since the $\alpha_{2}$ phase tends to contain more interstitials, namely oxygen, than the $\gamma$ phase, it takes place a scavenging effect in this phase lowering its interstitial concentration. The effect is an increase on the dislocation mobility at this phase and an increase in the alloy ductility. On the other hand, in single phase $\gamma$-TiAl as soon as the oxygen concentration reaches 250 at.ppm, precipitation of titanium oxides starts until total consumption of oxygen. In two-phase $\gamma$-TiAl alloys, the excess of oxygen is absorbed in $\alpha_{2}$ avoiding oxide formation and enhancing ductility.

As TiAl is extremely reactive, its production by foundry processes using traditional crucible and mould materials (usually metal oxides) is a difficult task, because ceramic-alloy interactions are always present. As a consequence, it is almost impossible to obtain titanium alloys castings free from contaminants. During the last 5 years the authors have done extensive research work in this field and have developed a melting and moulding technique based in ceramic materials $[4,5]$.

In this work, the effect of low level contamination was studied by SIMS. Special attention was given to oxygen concentration for samples obtained with different mould materials. The comparison of such profiles with hardness profiles, give insight in the significance of the oxygen concentration in the properties of the alloy and in the choice of the most suitable materials for TiAl production.

\section{Experimental}

Ti-48Al was induction melted in multi-layered $\mathrm{ZrO}_{2}+\mathrm{Y}_{2} \mathrm{O}_{3}$ crucibles. Cylindrical shaped samples were later poured into $\mathrm{ZrO}_{2}, \mathrm{SiO}_{2}$ and multi-layered $\mathrm{ZrO}_{2}+\mathrm{Y}_{2} \mathrm{O}_{3}$ moulds $\left(\mathrm{ZrO}_{2}\right.$ based, with $\mathrm{Y}_{2} \mathrm{O}_{3}$ inside contact layer), using the techniques described elsewhere [4-6].

After pouring and during the cooling and solidification stages, metal-mould interactions may occur. While the metal is in the liquid state, it may dissolve or react with the ceramic mould. As a consequence, oxygen and other impurities may diffuse from the mould material, into the liquid metal. When solidification starts, the interaction continues and composition gradients start to develop, from the interface into the castings inside. Such gradients lead to diffusion mechanisms in order to reach the equilibrium situation. As the temperature decreases, diffusion rates become smaller until they become negligible at low temperatures. As a consequence, chemical composition gradients can be found at room temperature from the surface to the castings inside, leading to significant changes in their properties. At that time a thick surface layer or hard case is formed, which is usually called " $\alpha$-case".

Cast specimens were cylinders $20 \mathrm{~mm}$ in diameter and $85 \mathrm{~mm}$ long and were poured at about $1550{ }^{\circ} \mathrm{C}$. Samples for characterization were collected from the middle section of them, by cutting the cylinders at half their height, and prepared using traditional metallographic techniques.

Since the diffusion rate of oxygen in TiAl is very high and its presence is known to affect the ductility and hardness of the alloy, the measurement and the knowledge of its variation are crucial to select proper ceramic materials for crucible/mould production. Therefore, microhardness was evaluated using a Shimadzu hardness tester (50 g load, for $15 \mathrm{~s}$ ) and SIMS was used to determine the diffusion profile of oxygen.

SIMS has been performed in a Multitechnique Surface Analysis System detailed described elsewhere [7]. A $4 \mathrm{keV} \mathrm{Ar}^{+}, 200 \mathrm{nA}$ beam focused in a $50 \mu \mathrm{m}$ diameter spot was used. Secondary ions produced by sputtering were mass analysed by a quadrupole type mass spectrometer. Both positive and negative spectra were taken. Base pressure during analysis was in the order of $10^{-9}$ mbar.

Samples were specially prepared for SIMS characterization by cutting them through a plane making a $15^{\circ}$ angle with the cylinder axis as described in the insets of Fig. 1. In this way, analysis could be performed in several points from the cylinder surface to the bulk, without the need of too long erosion times.

After cutting and polishing, samples were preserved in glycerol prior to their introduction in vacuum to avoid contamination or reactions with the atmosphere. Samples were then carefully washed with solvents and clamped in the stubs to be introduced in the analysis 



Fig. 1. Positive and negative ion spectra acquired in the spots shown by the inserts from a TiAl sample poured in a multi-layered $\mathrm{ZrO}_{2}+\mathrm{Y}_{2} \mathrm{O}_{3}$ mould.

chamber. Surface profiles (corresponding to cylinder in-depth profiles) were obtained by shifting the sample under analysis along one of the axis of an accurate $X Y Z$ manipulator. Increments of $20 \mu \mathrm{m}$ were used, starting from the non-polished side (the outer cylindrical surface). These increments correspond to about $5 \mu \mathrm{m}$ steps in depth, along the cylinder radius. Therefore, the acquired surface profiles could be easily converted in-depth profiles.

\section{Results and discussion}

In order to evaluate the main peaks in the samples, positive and negative ion spectra were taken in three different spots- the outer cylinder surface, in the inner polished section and in between, at the edge. These spectra are shown in Fig. 1 for the sample poured into the $\mathrm{ZrO}_{2}+\mathrm{Y}_{2} \mathrm{O}_{3}$ mould.

Outside the cylinder (the casting surface) the amount of oxygen is huge as expected. Other common contaminants such as alkalis, carbon and halogens were also found, some of these through deep in the sample. The strong variation of the oxygen content drastically affects the ionization probability of the sputtered particles, hence care should be taken in the discussion of the total amounts measured. This conclusion is corroborated by the difference between spectra in the total intensity detected, as revealed by the total of counts (more than one order of magnitude for $\mathrm{O}^{-}$).

The ratio of intensities of $\mathrm{O}^{-}$and $\mathrm{AlO}^{-}$was found to be a good indicator of the variation of oxygen concentration along the sample. The results obtained using three different moulds are shown in Fig. 2 (left scale). In the same figure, the results achieved with the microhardness measurements are also plotted (right scale). These measurements were performed in the $\alpha_{2}+\gamma$ and $\gamma$ microconstituents, but only the $\alpha_{2}+\gamma$ results are shown, since almost no variation were found in the hardness of the $\gamma$ microconstituents.

From Fig. 2, an obvious correlation between oxygen concentration and microhardness can be established, which agrees with different references for commercially pure Ti $[8,9]$ : for every sample, hardness variation and oxygen concentration profiles show the same development from the surface to the inside of casting.

Both profiles reveal two distinct regimes: first, starting from the casting wall, profiles exhibits a gradual decrease in oxygen content as function of the distance from the surface due to diffusion from ceramic during solidification. Then, a second regime starts characterized by constant values of both oxygen concentration and microhardness. However, this correlation is valid only for the lamellar $\alpha_{2}+\gamma$ microconstituent hardness, because on the $\gamma$ constituent hardness was found to be almost constant all over 


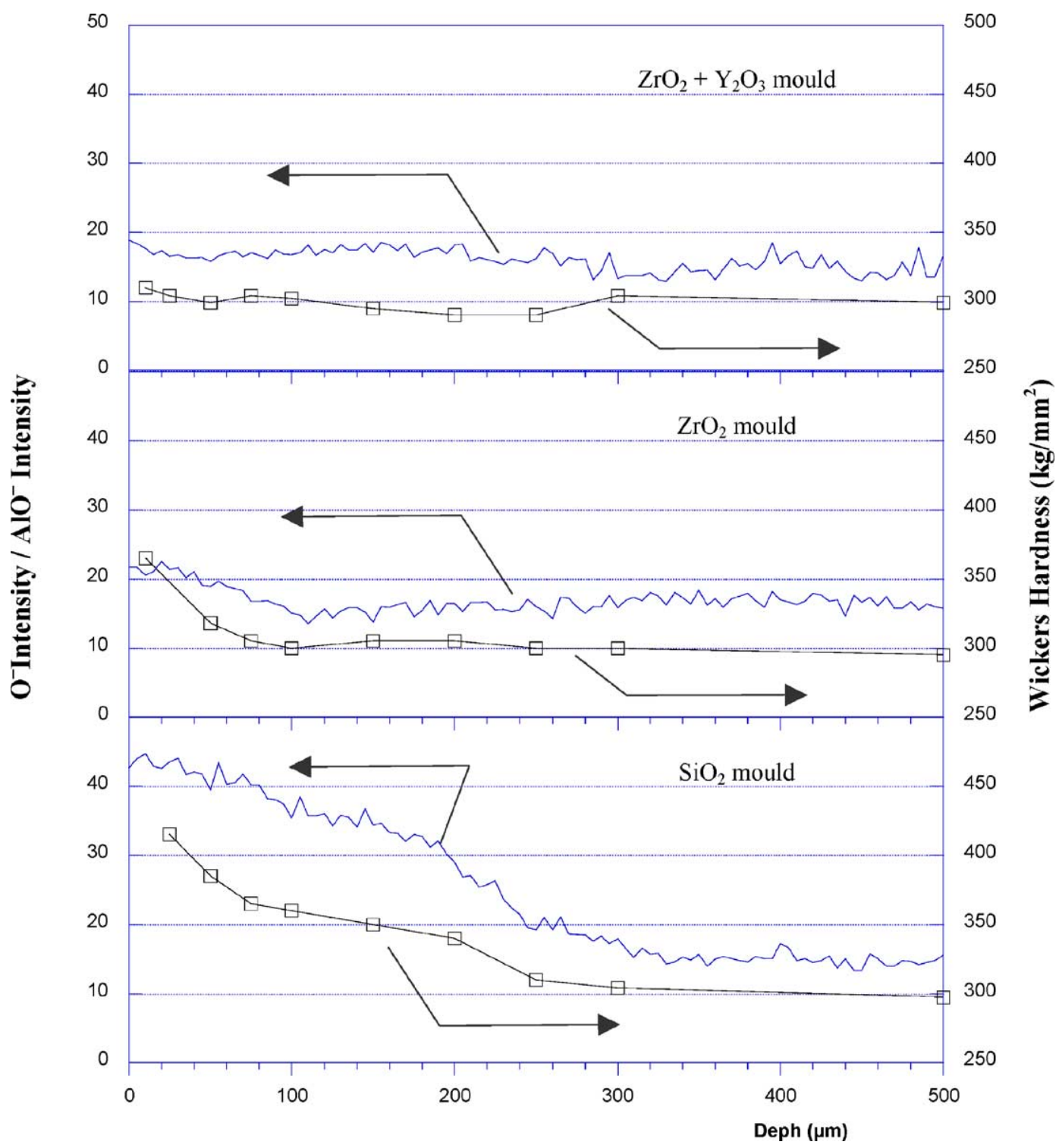

Fig. 2. Depth profiles for samples poured in different moulds. The left scale refers for the ratio of $\mathrm{O}^{-} / \mathrm{AlO}^{-}$which is a good indicator of the oxygen concentration. The right scale shows the hardness for the same depth. A clear relation between the oxygen distribution and the hardness is outstanding.

the samples. This fact confirms Menand findings [3], suggesting that oxygen dissolves preferentially on $\alpha_{2}$ phase and reveal a direct relation between these two parameters.

Fig. 2 shows that high oxygen concentrations is correlated to high hardness levels and oxygen levels are highest on samples obtained in $\mathrm{SiO}_{2}$ moulds and are minimum on those produced in $\mathrm{Y}_{2} \mathrm{O}_{3}$, which is indeed in accordance with the respective thermodynamic stability of those materials.

The absolute values for the ratio of intensities of $\mathrm{O}^{-}$and $\mathrm{AlO}^{-}$as shown in Fig. 2 is also meaningful. This ratio matched in the bulk for each of the tested moulds produced $(\approx 15)$ no matter the magnitude of contamination from the mould. This is in agreement with other measurements performed by the authors 
where the absolute amount of oxygen content was measured to be approximately the same for every sample $(\approx 0.28 \mathrm{wt} . \%)$. This leads to the conclusion that contamination takes place only in a very thin layer on the casting surface, not changing the overall concentration.

\section{Conclusions}

SIMS characterization of the casting samples allows the conclusion that the diffusion depth of oxygen strongly depends on the moulding material. Although the metal alloy and solidification time were the same for every sample, the difference in diffusion depth appears to be a consequence of different dissolution rates of the mould material, being maximum for $\mathrm{SiO}_{2}$ and minimum for $\mathrm{Y}_{2} \mathrm{O}_{3}$, among the tested materials.

A clear relation between hardness and oxygen concentration was found. The higher was the oxygen content the harder was the $\alpha_{2}$ microconstituent in the same depth.

Comparison of the moulding materials studied in this work, showed that multi-layered $\mathrm{ZrO}_{2}+\mathrm{Y}_{2} \mathrm{O}_{3}$ moulds produced the best $\gamma$-TiAl castings, since $\mathrm{ZrO}_{2}$ and $\mathrm{SiO}_{2}$ moulds lead to higher metal contamination and related changes in mechanical properties.
The developed technique based in traditional casting techniques combined with multi-layered $\mathrm{ZrO}_{2}+$ $\mathrm{Y}_{2} \mathrm{O}_{3}$ ceramic moulds seems to be a good alternative (lower-cost) to the actual processing routes of $\gamma$-TiAl castings.

\section{Acknowledgements}

This work was supported by the Portuguese Foundation for Science and Technology.

\section{References}

[1] Y.W. Kim, D.M. Dimiduk, JOM-J MIN met mat S43 (8 Aug 1991) 40-47.

[2] T.K. Roy, R. Balasubramaniam, A. Ghosh, Metall. Mater. Trans. A 27A (1996) 2993.

[3] A. Menand, A. Huguet, A. Nerac-Partaix, Acta Mater. 12 (1996) 4729.

[4] J. Barbosa, Ph.D. Thesis, University of Minho, Portugal, 2002.

[5] J. Barbosa, S. Ribeiro, C. Monteiro, Proceedings of the Materials Week 2001 Congress, Munich, Germany.

[6] J. Barbosa, S. Ribeiro, Int. J. Cast Met. Res. 12 (2000) 293.

[7] O.M.N.D. Teodoro, J.A.M.C. Silva, A.M.C. Moutinho, Vacuum 46 (1995) 1205.

[8] R.L. Saha, et al., Metall. Trans. B 21B (1990) 559.

[9] R.L. Saha, Tam Foundrymens soc 98 (1990) 253. 